land should yield an increasing volume of cash exports. The success of these schemes depends in the long run on other aspects of the territorial economy reaching a certain level of development and affording such projects as power, water supplies, transport and nucleus agricultural estates, the means to investigate and establish the cultivation and management techniques appropriate to small-holder crops, and that high priority be given to production industries which generate the cash exports to service capital investment overseas. The Corporation is already committed to nearly $£ 6$ million in some fourteen projects for local industrial development agencies.

Stress is also laid on the way the Corporation is placed to keep in touch with local circumstances and views. The Corporation believes that the presence on the spot of Corporation staff, ready to share the risks of local ventures by equity investment, en- genders a sense of partnership not present when development finance is provided only as block loans from abroad. The maintenance of the Corporation's offices and staffs in times of rapid political change certainly provides an essential element of economic continuity; the extent of the management organization implied in the fact that the Corporation itself has at least some responsibility fot the management of more than half the 102 continuing projects is seldom realized. Although there is less reference in this report to this training function, the importance of making every effort to train local men for executive posts of responsibility is fully recognized. Some success in this direction is reported in the Far East, in the Caribbean and West Africa, while in other parts of Africa the Corporation is concentrating, as a first step, on providing scholarships at agricultural and technical colleges and on project training schemes.

\title{
MINERAL TECHNOLOGY AT THE IMPERIAL COLLEGE OF SCIENCE AND TECHNOLOGY
}

YN 1952 the University of London established at 1 the Royal School of Mines a course in mineral technology leading to a B.Sc. degree, the first undergraduate course of its kind in the Commonwealth and one of the first in the world. In 1961 a new chair was founded (see Nature, 190, 1153; 1961) and the inaugural lecture of Prof. M. G. Fleming has now been published by the Imperial College of Science and Technology*.

Mineral technology, embracing as it does both the engineering and the scientific aspects of the separation of the valuable mineral constituents from their ores, has its origin in prehistoric times with man's selection and dressing of stones for his tools and weapons, and its long history is closely linked with that of civilization itself. Silver from the mines at Laurium built the Greek fleet that defeated Xerxes, and copper from Falun financed Sweden's part in the Thirty Years' War. During the twentieth century, more irreplaceable minerals have been consumed than in the whole previous history of the Earth. From 1911 to 1959 the world production of iron ore increased from about 130 million tons to 406 million, nickel ores from 24 to 290 thousand tons and sulphur and pyrites from some three million tons to eight times that figure. This expanding demand has necessitated the treatment of increasingly low-grade and complex deposits which in the past would have

- Mineral Technology-Progress and Problerns. Inaugural Lecture, December 5, 1961.) Pp. 79-98. By Prof. M. G. Fleming (London: Imperial College of Science and Technology. Distributed by been considered valueless, and mineral dressing which even fifty years ago was still essentially an art has now become a branch of industrial science in its own right. How important it is for Britain, not only to keep abreast of the latest developments in this field but also to play the fullest part in new research of all kinds, is evidenced by the fact that Britain no longer has control of enormous quantities of raw material which is necessary for her existence as a leading industrial nation. As a result of the granting of independence to many territories much more than half the mineral production of former members of the Empire has already passed out of Britain's hands.

It is in order to play its part in this that Prof. Fleming's Department has come into existence. Quite apart from its undergraduate work, the investigations already under way range from the determination of heats of adsorption, a study of the mechanism of adhesion of colloidal particles and the kinetics of solvent extraction, to dense-medium separation in hydrocyclones and the beneficiation of concentrates by pelletizing, roasting and leaching. This most interesting inaugural lecture concludes with an account of work on flotation in which the necessary reagents are introduced as a fine spray, the separation of ore from gangue being further improved by the application of an appropriate electrostatic charge whereby the droplets of reagent are attracted to the valuable minerals and actually repelled from the particles of gangue.

F. C. THOMPSON

\section{EVALUATION OF THE CARCINOGENIC HAZARDS OF FOOD ADDITIVES}

\footnotetext{
THE Joint Food and Agriculture Organization/ World Health Organization Expert Committee on Food Additives met in Geneva during December 12-19, 1960, and, in its fifth report* has recommended the following general basic principles:

*W.H.O. Tech. Rep. Ser., No. 220 (H.M.S.O., 1961).
}

(1) Food additives should be used for the benefit of the consumer; they should not be permitted for any deceptive or misleading purpose.

(2) The use of certain food additives is justified since the present position with respect to world food supplies makes it imperative that good techni- 
cological procedures should be developed and used to a maxima extent.

(3) Food materials and all chomicals and processes at present in use for the preparation and distribution of food should be subjected to adequato examination to ensure minimum risk in use, if this has not already been done, or unless previous knowledge indicatos that this is unnecessary.

(4) All chemicals or processes proposed in the futuro should be subjected to adequate examination to minimize risk before being accepted for use.

(5) The presence of carcinogenic substances in food might be a significant factor in the occurrence of what is considered to be spontaneous cancer in man and animals.

(6) Since dose-response relationships have been demonstrated in the caso of carcinogenic agents, the reduction of carcinogenic substances in food to the lowest practicable lovel may be one of the effective measures towardis cancer prevention.

(7) Many factors may influonce dose-response in carcinogenesis. Their complexities aro such that it is agreed that no assuredly safo level for carcinogens in human food can bo determined from experimontal findings at the present time.

(8) The elimination, or at least the reduction to a minimum, of all provod carcinogenic substances in the diet of man and of animals used as human food is a worth-while objective.

In recent years a number of food additives or food contaminants have been suspected of being carcinogenic. As a practical approach to the problems aris- ing in this field, the Committee has reviewed the ovidence availablo and the action taken with regard to a number of these substances. Many points of interest were rovealed, of which the most important aro

(a) The apparent lack of information on the toxicity or potential carcinogenity of many food additives.

(b) The inadoquacy of the design, execution and interpretation of some experiments or of reported information in some of the publications in this field and the frequent lack of corroborative evidence.

(c) The noed for detailed pathological evaluation of any lesion observed in exporimental studies.

(d) The difficulties arising in interpretation of local sarcoma formation at the site of the injection.

(e) The difficulty of completoly excluding, at the present time, carcinogonic contaminants from food, from processos used in the preparation of food, and from substances coming into contact with food.

(f) The possibility that some natural constituents of the diet or even an essential nutrient, such as selenium, may constitute a carcinogenic risk. Clearly, these substances cannot be completely excluded from the diet.

(g) The difficulty of carrying out and intorpreting opidemiological studies.

(h) The wide variety of food colours, many of which do not appear to have been adequately tested, including the 'permitted' lists of different countries.

(i) The necessity for separate assessment of the carcinogenic risk for each individual substance.

\section{EARLY FOSSIL RODENTS AND THEIR EVOLUTION}

$\mathrm{T}$ $\mathrm{HE}$ literature of science overflows with immature works, but at rare intervals a magnum opus, the seasoned fruit of many years patient study, is offerod for our digestion. Such is The Early Tertiary Rodents of the Family Paramyidae, by Albort E. Wood, published in the Trans. Amer. Phil. Soc. (New Series, 52, part 1. Pp. 261. Philadelphia: American Philosophical Society, 1962. 6 dollars). Behind the innocuous title nestles a major contribution to the study of fossil rodents, a veritable landmark in mammalian palæontology, and a wealth of detailed anatomical, taxonomic and stratigraphic observations for the student of evolution.

The paramyids comprise the earliest known rodents of the Upper Palæocene and Eocene. When last reviewed by W. D. Matthew in $1910^{1}$ he was able to deal exhaustively with the group in thirty pages. The size of the present work is a measure of the vast quantity of additional material available for study half a century later. Wood begins with a review of the history of the classification of the paramyids, discussing the views of earlier writers on the importance of the paramyids in the ovolution of rodents.

All but 30 pages of this great work are devoted to a systematic treatise of the family paramyidae. Wood states ho has examined approximately a thousand specimens, referred to 22 gencra and 78 species, ranging from the Upper Palæocene to Upper Oligocene, mainly from North America but including European forms. In several instances nearly complete skeletons were available. Where material in a sample was adequate ho has made variation studies; incisor teeth have been carefully examined and found to be of considerable systematic value. Each species is monographed, its probable affinities dis. cussed and where possible the functional interpretation of its characteristics are suggested. These details enabled Wood, for example, to reconstruct Paramys delicatus as a rat-like animal, rather than the squirrel-like reconstruction of Matthew. In two species Wood has been able to recognize a serios of sub-specics-material for so detailed a study of gens or rassenkreis rarely obtains in mammalian palæontology. The illustrations are admirable, clearly drawn and well printed: it is unfortunate that the phylogenetic tree could not have been threedimensional.

Following the systematic troatise, Wood discusses the interrelationships of paramyids, evolutionary trends within the family, relationships to later rodents, rodents subordinal classification, evolutionary rates in paramyids and the origin of rodents. Several of the opinions and interpretations set out here have already appeared in print in earlier writings of the author; nevertheless the summary accompanying the monograph is usoful in restating Wood's case alongside his evidence.

In discussing evolutionary trends Wood distin. guishes three sories. First, those that can be followed in all or nearly all lines within the family, representing results of seloctive pressures for increased rodent adaptation; these include continuously growing incisors and reduction of pre-molar dentition. Secondly, those which represent divergent trends characteristic of one or more sub-families as a result 